\title{
Non-steroidal anti-inflammatory drugs and gastroprotection in primary health care users
}

Driton Shabani ${ }^{1}$, Ardiana Murtezani², Bernard Tahirbegolli ${ }^{3}$, Argjira Juniku-Shkolollii ${ }^{4}$ Zana Ibraimi ${ }^{1}$

1) Department of Pharmacy, Faculty of Medicine, University of Prishtina, Kosovo

2) Physical Medicine and Rehabilitation Clinic, University Clinical Center of Kosovo

3) Heimerer College, Professional Education in Health / Vocational Field Nursing, Prishtina, Kosovo

4) Department of Gastrohepatology, University Clinical Center of Kosovo

DOI: $10.15386 / \mathrm{mpr}-1533$

Manuscript received: 02.12.2019

Received in revised form: 29.01 .2020

Accepted: 13.02 .2020

Address for correspondence:

zibraimi@yahoo.com

This work is licensed under a Creative Commons Attribution-NonCommercialNoDerivatives 4.0 International License

\begin{abstract}
Objective. The aim of this study is to assess the prevalence of gastroprotection and identify the main factors that influence the taking of protective drugs by the adult population treated with non-steroidal anti-inflammatory drugs (NSAID).

Methods. This study was cross-sectional, conducted by including a contingent of 800 users of primary health care services $(n=369,46 \%$ males and $n=431,54 \%$ females). Included in the study were individuals of both genders aged $18+$ who sought counselling or treatment during the three-month period. The data collection of this study was based on the completion of a structured questionnaire, which included questions related to the use of NSAIDs, the way these drugs were prescribed and administered and the simultaneous taking of gastroprotective drugs.

Results. The prevalence of the gastroprotective drugs use was higher among the elderly, individuals living in urban areas, those with higher education, those with daily use of NSAID, individuals receiving prescriptions from their own doctors, and those suffering from side effects from the use of NSAID, as well as subjects that had a longer duration of NSAID use. Diclofenac was the most prescribed NSAID. Gastric pain and dizziness were the most experienced side effects.

Conclusion. This paper demonstrates the need to improve the quality of primary health care service through informing and educating patients regarding the need to take gastro-protective drugs for those at high risk of adverse effects manifested by the use of NSAIDs.
\end{abstract}

Keywords: non steroidal anti-inflammatory drugs, gastroprotection, prevalence

\section{Introduction}

Nonsteroidal anti-inflammatory drugs (NSAIDs) represent a major class of analgesic drugs used in musculoskeletal disorders, migraine, and osteoarthritis [1] and have remained the firstline for controlling pain and inflammation in these conditions [2].

They are frequently associated with upper gastrointestinal (GI) adverse effects including dyspepsia, endoscopic ulcers, serious ulcer complications (bleeding, perforation, and obstruction), which can lead to hospitalization and mortality $[3,4]$.

Gastrointestinal risk factors associated to NSAIDs use are advanced age, higher doses of NSAID, and probably long-term use of NSAIDs [1]. The presence of comorbidities, especially a history of peptic ulcer disease, Helicobacter pylori (H. pylori) infection, smoking, chronic alcohol abuse, and concomitant use of other medications increase the risk of developing NIG $[2,5]$. Gastroprotective agents (GPA) are highly effective preventive strategies [6]. They can substantially reduce the morbidity and mortality associated with long-term NSAID use [7].

Clinical guidance on NSAID use [5] recommended concomitant prescription of nonselective NSAID (nsNSAID) with a GPA such as misoprostol, a double-dose histamine-2 receptor antagonist (H2RA) and a proton pump inhibitor (PPI) and use of a cyclooxygenase (COX)-2 selective inhibitor instead of an nsNSAID [8,9].

Overall, the use of NSAID is unfortunately hampered by their 
gastrointestinal toxicity, ranging from light indigestion to serious complications including severe bleeding ulcers, as well as perforation and obstruction of the digestive tract [10]. It has been shown and proven in many studies that an endoscopically confirmed ulcer may develop in around $15 \%$ - $30 \%$ of chronic NSAID users and serious complications may occur in approximately $2 \%-4 \%$ of developed ulcers $[11,12]$. In USA, NSAID is thought to cause about 7,000 to 16,500 deaths each year [13]. Therefore, preventing gastrointestinal toxicity associated with the use of NSAID (with or without any criteria) has become an important clinical problem as well as a serious public health issue throughout the world [14].

This paper aims to assess the prevalence of gastroprotection and identify the main factors that influence the taking of protective drugs among the adult population using primary health care services, who are treated with NSAIDs.

\section{Material and methods}

This study was cross-sectional, conducted by including a contingent of 800 users of primary health care services over a period of three months.

\section{The population in the study}

Included in the study were individuals of both genders aged $18+$ who sought counselling or treatment from primary health care services for a period of three months.

The calculation of the sample size of primary health care services users was enabled from the WIN-PEPI program (Program for Epidemiologists, Windows version) [15].

The calculation of the minimum number needed for participation in the study was based on many hypotheses related to the prevalence and determinants of patients' gastroprotection (users of primary health care services) including socio-demographic characteristics (age, sex, place of residence, education, employment, financial situation, social strata) as well as the clinical profile of the patients (NSAID use, description modalities, duration of NSAID intake, and adverse effects).

Based on different hypotheses, in order to calculate the size of the sample of patients needed, the alpha error rate (first type error) was set at 5\%, while the power of the study was set at $80 \%$, in accordance with the principles and methodology procedures for quantitative scientific research $[15,16]$.

Based on the above considerations, the minimum required number of samples of primary health care users was estimated at 670 individuals. In order to increase the power of the study, 850 individuals were invited to participate.

In conclusion, according to the adopted approach, 850 participants of primary health care services (individuals aged $18+$ years of age of both sexes) were invited to participate in the study.

Of the 850 targeted individuals for inclusion in the study, 50 refused the interview because of lack of time, severe illness, or inability to attend the study.

Thus, the final patient sample included a contingent of 800 primary health care users $(n=369,46 \%$ males and $\mathrm{n}=431,54 \%$ females) with a general degree of participation in the study of: $800 / 850=94 \%$. Thus, the degree of participation in the study was very satisfactory.

\section{Data Collection}

The data collection of this study was based on the completion of a structured questionnaire. The study questionnaire included questions related to the use of NSAID and the modalities for the prescription and administration of these drugs, including their take-up time, the potential side effects, and simultaneous taking of gastroprotective drugs.

Beyond the basic questions of the prevalence assessment instrument and the gastroprotection clinical determinants, the administered questionnaire included demographic data (age, gender, place of residence), socioeconomic data (employment status, education, economic level, social strata) as well as data on the use and degree of satisfaction with the quality of primary health care services.

The study was preliminarily approved by the Republic of Kosovo Bio-Medical Ethics Committee. All patients included in this paper gave their consent to participate in the study after being informed of the study purpose and objectives and the detailed questionnaire administration procedures.

\section{Statistical Analysis}

In the statistical analysis differences between normally distributed continuous variables were tested with the Student t-test and differences between categorical variables with the chi-square test. For the continuous data, Mann-Whitney U test were applied.

Statistical analysis was performed with Statistical Package for Social Sciences, (SPSS) 19.0 software. A p value $<0.05$ was considered significant.

\section{Results}

We analyzed the correlation between age and gender (Table I) and obtained that among men, the average age of the study subjects $(\mathrm{N}=369)$ was $53.7 \pm 16.9$ years, while in women $(\mathrm{N}=431)$ this value was $47.4 \pm 16.5$ years.

Table I. Distribution by age and gender in the sample of health service users.

\begin{tabular}{l|c|c}
\hline Age & Men (age) & Women (age) \\
\hline $\begin{array}{l}\text { Average } \\
\begin{array}{l}\text { Median (interquartile } \\
\text { distance) }\end{array}\end{array}$ & $53.71 \pm 16.94$ & $47.43 \pm 16.53$ \\
$\begin{array}{l}\text { Range (minimum - } \\
\text { maximum) }\end{array}$ & $18-92$ & $18-85$ \\
$\begin{array}{l}\text { Age group: } \\
\leq 40\end{array}$ & $94(25.5)$ & $170(39.4)$ \\
$\begin{array}{l}41-59 \\
\geq 60\end{array}$ & $119(32.2)$ & $139(32.3)$ \\
Total & $156(42.3)$ & $122(28.3)$ \\
& $369(100.0)$ & $431(100.0)$
\end{tabular}


On the other hand, the median age among males was 54.0 years (interquartile distance: $40.0-68.0$ years), while in females it was 46.0 years (interquartile distance: 33.0-60.0 years).

The age range for males was from 18 years (minimum) to 92 years (maximum), whereas in females it was from 18 years of age (minimum) to 85 years (maximum).

The largest cohort of patients was male with more than 60 years $(42.3 \%)$.

There was evidence of a statistically significant difference in the mean age value between males and females (Student ' $\mathrm{t}$ ' test: $\mathrm{P}<0.001$ ).

Based on the obtained results, we managed to confirm that about $60 \%$ of individuals resided in urban areas while $40 \%$ of them resided in rural areas (Table II). About $33 \%$ of patients had a low level of education, while $27 \%$ had a higher education level. The unemployment rate was relatively high; about $23 \%$ of individuals reported being unemployed. The relatively high unemployment rate was also reflected in a low economic level, reported by about $36 \%$ of patients, while only about $7 \%$ stated that they had a high economic level. Regarding the obtainment of primary health care services, 257 (32.1\%) patients reported that they had never visited their health center during the past 12 months, $456(57.0 \%)$ reported having visited $1-2$ times, while $87(10.9 \%)$ stated that they had visited the health center at least three times during the last year.

Table III presents the distribution of clinical characteristics by gender. Overall, about $27 \%$ of the individuals involved in this study were diagnosed with "dorsalgia" (based on the ICD-10 classification); about $13 \%$ had cervical-cranial syndrome; about $15 \%$ had spondylosis; about $14 \%$ had headaches; while the rest of about $31 \%$ had other diagnoses including musculoskeletal disorders, or other diseases. There was no evidence of any statistically significant difference in the distribution of clinical diagnosis between male and female patients (chisquare test: $\mathrm{P}=0.09$ ).

Table II. Distribution of demographic and socio-economic factors in the sample of health service users.

$\begin{array}{lc}\text { Characteristic } & \text { No: } 800 \text { patients } \\ \text { Residing in: } & \\ \text { Urban area } & 484(60.5)^{*} \\ \text { Rural area } & 316(39.5) \\ \text { Education level: } & \\ \text { Low } & 266(33.3) \\ \text { Middle } & 317(39.6) \\ \text { High } & 217(27.1) \\ \text { Employment status: } & \\ \text { Unemployed } & 183(22.9) \\ \text { Other (employed or retired) } & 617(77.1) \\ \text { Economic level: } & \\ \text { Low } & 287(35.9) \\ \text { Middle } & 456(57.0) \\ \text { High } & 57(7.1) \\ \text { Health check-ups in the last year: } & \\ 0 & 257(32.1) \\ 1-2 & 456(57.0) \\ \geq 3 & 87(10.9)\end{array}$

"Absolute numbers and percentages per column (in brackets).

Generally, the prevalence of daily use of NSAID was about $24 \%(\mathrm{~N}=191)$. On the other hand, the majority of patients $-76 \%(\mathrm{~N}=609)$ - reported the use of NSAID only if needed (i.e., in order to manage the symptoms of their respective illnesses).

There was evidence of a statistically significant change in the prevalence of daily use of NSAID, where male patients reported a higher prevalence compared to females (about $27 \%$ vs. $21 \%$ respectively; chi-square test: $\mathrm{p}=0.056)$.

Table III. Distribution of clinical characteristics by gender in the sample of health service users.

\begin{tabular}{|c|c|c|c|c|}
\hline Clinical characteristics & $\operatorname{Men}(\mathrm{N}=369)$ & Women $(\mathrm{N}=431)$ & Total $(\mathrm{N}=\mathbf{8 0 0})$ & $\mathbf{P}^{\dagger}$ \\
\hline $\begin{array}{l}\text { Diagnosis (ICD-10) } \\
\text { M54 (dorsalgia) } \\
\text { M53 (cervical-cranial syndrome) } \\
\text { M43 (spondylosis) } \\
\text { R51 (headache) } \\
\text { Other }\end{array}$ & $\begin{array}{c}98(26.6)^{*} \\
47(12.7) \\
64(17.3) \\
37(10) \\
123(33.3)\end{array}$ & $\begin{array}{c}119(27.6) \\
58(13.5) \\
53(12.3) \\
77(17.9) \\
124(28.9)\end{array}$ & $\begin{array}{l}217(27.1) \\
105(13.1) \\
117(14.6) \\
114(14.3) \\
247(30.9)\end{array}$ & 0.092 \\
\hline $\begin{array}{l}\text { NSAID use: } \\
\text { Daily } \\
\text { As needed }\end{array}$ & $\begin{array}{l}100(27.1) \\
269(72.9)\end{array}$ & $\begin{array}{c}91(21.1) \\
340(78.9)\end{array}$ & $\begin{array}{l}191(23.9) \\
609(76.1)\end{array}$ & 0.056 \\
\hline $\begin{array}{l}\text { Prescribed by: } \\
\text { Doctor } \\
\text { Pharmacist }\end{array}$ & $\begin{array}{l}197(53.4) \\
172(46.6)\end{array}$ & $\begin{array}{l}229(53.1) \\
202(46.9)\end{array}$ & $\begin{array}{l}426(53.3) \\
374(46.8)\end{array}$ & 0.943 \\
\hline
\end{tabular}

${ }^{*}$ Absolute numbers and percentages by columns (in brackets).

${ }^{\dagger}$ Comparison of male-female ratio through Hi-square test, while comparison of the duration of NSAID use through the Mann-Whitney test. 
Table IV. Distribution of adverse effects according to gastro-protection status in the sample of health service users.

\begin{tabular}{|c|c|c|c|}
\hline Risk factor & $\begin{array}{l}\text { Without protection } \\
\qquad(\mathrm{N}=\mathbf{5 4 1})\end{array}$ & $\begin{array}{l}\text { Gastro-protection } \\
(\mathrm{N}=\mathbf{2 5 9})\end{array}$ & $\mathbf{P}^{\dagger}$ \\
\hline $\begin{array}{l}\text { Age group } \\
\leq 40 \\
41-59 \\
\geq 60\end{array}$ & $\begin{array}{c}201(37.2)^{*} \\
198(36.6) \\
142(26.2)\end{array}$ & $\begin{array}{c}63(24.3) \\
60(23.2) \\
136(52.5)\end{array}$ & $<0.001$ \\
\hline \multicolumn{4}{|l|}{ Adverse effects: } \\
\hline $\begin{array}{l}\text { No } \\
\text { Yes }\end{array}$ & $\begin{array}{l}332(61.4) \\
209(38.6)\end{array}$ & $\begin{array}{l}74(28.6) \\
185(71.4)\end{array}$ & $<0.001$ \\
\hline Duration of use (years) & $4.30 \pm 3.25$ & $7.56 \pm 4.94$ & $<0.001$ \\
\hline
\end{tabular}

Regarding the prescription of NSAID, about $53 \%$ of patients reported that their medicines were prescribed by their respective doctors, while the rest of the patients of about $47 \%$ reported obtaining their drugs directly from the pharmacy.

The prevalence of gastroprotection in this representative group was $259 / 800=32.4 \%$ of cases (Table IV).

As shown in table IV, the prevalence of gastroprotective drugs use was higher among elderly subjects (older than 60 years of age) compared to younger individuals (40 years and older), and this change was statistically very significant (Hi-square test: $\mathrm{p}<0.001$ ).

As for the adverse effects caused by the use of NSAIDs, about $49 \%$ of patients reported having adverse effects associated with the use of such medicines, while about $51 \%$ reported no adverse effects from using NSAIDs. The prevalence of gastroprotective drugs use was much higher among subjects who had adverse effects from the use of NSAIDs compared to those who did not have adverse effects from administering these drugs. This difference between the two groups was statistically very significant (chi-square test: $\mathrm{p}<0.001$ ).

The use of gastroprotective drugs was much higher in subjects with a longer duration of NSAID use compared to those who had a shorter duration of administering such drugs. This difference between the two groups was statistically very significant (Mann-Whitney test: $\mathrm{p}<0.001$ ).

The frequencies of NSAIDs prescribed to the subjects are presented in table V. The most commonly prescribed NSAID subgroup was non-selective NSAIDs. Ibuprofen was the most frequently prescribed NSAID (40.4\% of subjects). The next most commonly prescribed traditional NSAIDs were diclofenac (28.1\% of subjects).

Proton Pump Inhibitors (PPIs) were the most commonly used drugs for gastroprotection in patients receiving NSAIDs: $54 \%$ of the respondents referred that they used PPIs, while $25 \%$ referred the use of H2-blockers (Table VI).

Table V. Used NSAIDs based on their COX-1 or COX-2 selectivity.

\begin{tabular}{l|c|c} 
Used gastroprotective agents & Frequency & Percentages \\
PPI & 139 & 53.67 \\
H2RAs & 65 & 25.10 \\
Antacids & 49 & 18.92 \\
Prostaglandin E1 analogues & 6 & 2.32
\end{tabular}

PPI - Proton Pump Inhibitors; H2RAs - Histamine 2 -receptor antagonists

Table VI. Distribution of used gastroprotective agents by frequencies and percentages.

\begin{tabular}{lcc} 
Used gastroprotective agents & Frequency & Percentages \\
\hline PPI & 139 & 53.67 \\
H2RAs & 65 & 25.10 \\
Antacids & 49 & 18.92 \\
Prostaglandin E1 analogues & 6 & 2.32 \\
PPI - Proton Pump Inhibitors; H2RAs - Histamine 2 -receptor \\
antagonists
\end{tabular}

Based on our results we found that around $49 \%$ of the patients had gastrointestinal symptoms. The main NSAIDs-related gastrointestinal adverse event was gastric pain (Table VII).

Table VII. Adverse effects of NSAIDs use among study group.

$\begin{array}{lcc}\text { Adverse effects } & \text { Frequency } & \text { Percentages } \\ \text { Peptic ulcer } & 23 & 5.8 \\ \text { Nausea } & 64 & 16.2 \\ \text { Dizziness } & 90 & 22.8 \\ \text { Gastric pain } & 94 & 23.9 \\ \text { Abdominal pain } & 69 & 17.5 \\ \text { Gastro-intestinal bleeding } & 10 & 2.5 \\ \text { Indigestion } & 5 & 1.3 \\ \text { Vomiting } & 6 & 1.5 \\ \text { Diarrhea } & 28 & 7.1 \\ \text { Other } & 5 & 1.3\end{array}$




\section{Discussion}

The current study is among the few research works undertaken in the Republic of Kosovo on an important topic related to the use of gastroprotective drugs in users of primary health care services in this society undergoing significant social, economic and political transition.

In our study, regarding the description of NSAIDs, about half of patients reported that their medicines were prescribed by their respective doctors, while the rest of the patients reported obtaining their drugs directly from the pharmacy. This is in accordance with other researches $[12,17]$ that the majority of subjects $(53 \%)$ were placed on NSAIDs by medical practitioners.

Ibuprofen was the most frequently prescribed NSAID followed by Diclofenac and this is noted to be the most widely used NSAID in the world and this is despite its side effects reported in several studies $[18,19]$. The usage might be attributed to its efficacy in pain management. In agreement with these findings, a study [20] stated the same, that the excessive consumption is associated with a lowto-intermediate risk of GI complications, depending on the doses used $[4,21,22]$.

In the present study, $541(67.6 \%)$ patients were prescribed an NSAID without a gastroprotective agent. In concordance with us, a study [21] of 311 patients over 59 years of age were prescribed an NSAID without a gastroprotective agent. They analyzed hospital admissions for NSAID-induced gastropathy and found that the most common risk factors for these admissions were age and concomitant treatments with other drugs that enhance the GI toxicity of NSAIDs. The same study found that a large proportion of patients who met the criteria for gastroprotection were not prescribed gastroprotective drugs [21]. The review [23] found that eight of the 11 studies reported that large proportions of patients with gastrointestinal risk factors (including age $\geq 65$ years) were not receiving appropriate gastroprotection.

Our results confirmed previous published evidence [24-27] that the prescription rate of GPAs was low (32\% for NSAIDs in our study group). This rate increased to $53 \%$ when only patients aged $\geq 65$ years old were considered. The use of GPAs was much higher in subjects with a longer duration of NSAID use (5.98 years). A cross-sectional study conducted in Albania, similar to this one, included a representative sample of 610 individuals receiving NSAIDs. Gastroprotective therapy was reported in 30 percent of the total sample of study participants [26]. Also, in another two studies $[25,27] 33.3 \%$ respectively $40 \%$ of subjects were taking gastroprotective drugs.

Our results are consistent with others in which $50 \%$ of the patients, $\geq 65$ years old taking NSAIDs, were not receiving gastroprotection [28].

The low use of GPAs in patients receiving NSAIDs may be due to the neglect of the gastrointestinal risks associated with these drugs, either by patients or by primary care physicians. This is a global problem, which may be related to the non-serious contact between doctors from tertiary centers to primary care physicians [29]. The percentage of physicians who will always prescribe GPAs in patients with gastrointestinal risk factors is low, except for patients with previous history of complicated peptic ulcer. Our results suggest that more than half of patients receiving NSAIDs with an indication for gastroprotection will not receive it. These results reveal an incomplete compliance with existing clinical practice recommendations $[8,30]$. Some observational studies have confirmed this low use of gastroprotection strategies in patients receiving NSAIDs with gastrointestinal risk factors with prescription rates of only $10-39 \%$ in patients with at least one risk factor [31].

Regarding the adverse effects caused by the use of NSAIDs, our study evidenced about $49 \%$ of patients reporting side effects. Similar to us, a study by Teslim et al. [17] found that the number of patients who had experienced the listed side effects was significantly higher than those who had not. Moreover, the results of this study were fully compliant with results from a study by Cottrell et al. [32] and and Albsoul-Younes et al. [33], who reported that more than half of participants $(67 \%)$ in their studies had experienced at least one side effect.

There are same views in literature [2,3,27,34] when it comes to NSAIDs-related gastrointestinal adverse events. Based on our results the main NSAIDs-related gastrointestinal adverse events were gastric pain.

Likewise, a quarter of the patients received histamine type-2 receptor antagonists, while approximately half of the patients received proton pump inhibitors (PPIs), much the same in the studies of Moore et al. [1] and Al Khaja et al [25].

Kosovo as a post conflict country faces the lack of positive laws and normative acts in order to create sustainable structures, which will regulate and manage General Health Policies and Public Health Programs [35].

Based on the findings of this study, we recommend that proper use of gastroprotective therapy for NSAID users should be immediately implemented in Kosovo, as inadequate use of these drugs causes ethical and economic concerns. Further, this study recommends that prescriptions and medical descriptions follow rigorous protocols and be based on clear guidelines for the prevention of gastrointestinal damage after NSAID therapy among persons with high risk.

The present study has a number of strengths and weaknesses. The strengths include the sampling method, which ensures a fair representation of Kosovar patients consulted for rheumatic and musculoskeletal diseases in primary care, and the attendance was relatively high. The main limitation of this study concerns the source of the data collected. We may have underestimated NSAID consumption in this population, as these drugs can be taken without a prescription. As such, the true rate of NSAID use may be higher than reported here. 


\section{Conclusion}

The results of this paper demonstrate the need to improve the quality of primary health care services through informing and educating patients regarding the need to take gastro-protective drugs for those at high risk of adverse effects manifested by the use of NSAIDs.

The findings of this paper should impose the design and implementation of health policies, strategies, programs and evidence-based activities in order to improve the communication between doctors and health personnel with the general population throughout the territory of the Republic of Kosovo.

\section{References}

1. Moore RA, Derry S, Simon LS, Emery P. Nonsteroidal antiinflammatory drugs, gastroprotection, and benefit-risk. Pain Pract. 2014;14:378-395.

2. Unified Clinical Protocol for Primary and Secondary Medical Care Peptic Ulcer of Stomach and Duodenum in Adults, Ukraine, 2014 Sep. Available at: http://mtd.dec.gov.ua/

3. Pilotto A, Franceschi M, Maggi S, Addante F, Sancarlo D. Optimal management of peptic ulcer disease in the elderly. Drugs Aging. 2010;27:545-558.

4. Hunt R, B Lazebnik L, C Marakhouski Y, Manuc M, Gn R, S Aye K, et al. International Consensus on Guiding Recommendations for Management of Patients with Nonsteroidal Antiinflammatory Drugs Induced Gastropathy-ICON-G. Euroasian J Hepatogastroenterol. 2018;8:148-160.

5. Lanza FL, Chan FK, Quigley EM; Practice Parameters Committee of the American College of Gastroenterology. Guidelines for prevention of NSAID-related ulcer complications. Am J Gastroenterol. 2009;104:728-738.

6. Targownik LE, Thomson PA. Gastroprotective strategies among NSAID users: guidelines for appropriate use in chronic illness. Can Fam Physician. 2006;52:1100-1105.

7. Rostom A, Dube C, Wells G, Tugwell P, Welch V, Jolicoeur E, et al. Prevention of NSAID-induced gastroduodenal ulcers. Cochrane Database Syst Rev. 2002;(4):CD002296.

8. Burmester G, Lanas A, Biasucci L, Hermann M, Lohmander $\mathrm{S}$, Olivieri I, et al. The appropriate use of non-steroidal anti-inflammatory drugs in rheumatic disease: opinions of a multidisciplinary European expert panel. Ann Rheum Dis. 2011;70:818-822.

9. Rostom A, Moayyedi P, Hunt R; Canadian Association of Gastroenterology Consensus Group. Canadian consensus guidelines on long-term nonsteroidal anti-inflammatory drug therapy and the need for gastroprotection: benefits versus risks. Aliment Pharmacol Ther. 2009;29:481-496.

10. Yuan JQ, Tsoi KK, Yang M, Wang JY, Threapleton DE, Yang $\mathrm{ZY}$, et al. Systematic review with network meta-analysis: comparative effectiveness and safety of strategies for preventing NSAID-associated gastrointestinal toxicity. Aliment Pharmacol Ther. 2016;43:1262-1275.

11. Singh G, Fort JG, Goldstein JL, Levy RA, Hanrahan PS, Bello AE, et al. Celecoxib versus naproxen and diclofenac in osteoarthritis patients: SUCCESS-I Study. Am J Med. 2006;119:255-266.

12. Abraham NS, El-Serag HB, Johnson ML, Hartman C, Richardson P, Ray WA, et al. National adherence to evidencebased guidelines for the prescription of nonsteroidal anti-inflammatory drugs. Gastroenterology. 2005;129:1171-1178.

13. Cryer B. NSAID-associated deaths: the rise and fall of NSAID-associated GI mortality. Am J Gastroenterol. 2005;100:1694-1695.

14. Barnard L, Lavoie D, Lajeunesse N. Increase in nonfatal digestive perforations and haemorrhages following introduction of selective NSAIDs: a public health concern. Drug Saf. 2006;29:613-620.

15. Abramson JH. Computer Programs for Epidemiologists: WIN- PEPI, version 11.43; 2014. Available from: http://www.brixtonhealth.com/pepi4windows.html

16. American College of Rheumatology Ad Hoc Group on Use of Selective and Nonselective Nonsteroidal Antiinflammatory Drugs. Recommendations for use of selective and nonselective nonsteroidal antiinflammatory drugs: an American College of Rheumatology white paper. Arthritis Rheum. 2008;59:1058-1073.

17. Oluwafisayo AJ, Mlenzana NB, Shamila M, Nesto T, Grace M. Side effects of non-steroidal anti-inflammatory drugs: The experience of patients with musculoskeletal disorders. Am J Public Health Res. 2014;2:106-112.

18. Kearney PM, Baigent C, Godwin J, Halls H, Emberson JR, Patrono C. Do selective cyclo-oxygenase-2 inhibitors and traditional non-steroidal anti-inflammatory drugs increase the risk of atherothrombosis? Meta-analysis of randomised trials. BMJ. 2006;332:1302-1308.

19. Vonkeman HE, Brouwers JR, van de Laar MA. Understanding the NSAID related risk of vascular events. BMJ. 2006;332:895-898.

20. Warlé-van Herwaarden MF, Koffeman AR, Valkhoff VE, 't Jong GW, Kramers C, Sturkenboom MC, et al. Time-trends in the prescribing of gastroprotective agents to primary care patients initiating low-dose aspirin or non-steroidal anti-inflammatory drugs: a population-based cohort study. Br J Clin Pharmacol. 2015;80:589-598.

21. Marco Garbayo JL, Koninckx Cañada M, Pérez Castelló I, Faus Soler MT, Fuster Torres R, Moncho Escrivà M. Crosssectional analysis of retrospective case series of hospitalisations for gastropathy caused by non-steroidal anti-inflammatory treatment: risk factors and gastroprotection use. Eur J Hosp Pharm. 2017;24:355-360.

22. Helin-Salmivaara A, Huupponen R, Virtanen A, Lammela J, Klaukka T. Frequent prescribing of drugs with potential gastrointestinal toxicity among continuous users of nonsteroidal anti-inflammatory drugs. Eur J Clin Pharmacol. 2005;61:425-431.

23. Moore RA, Derry S, Phillips CJ, McQuay HJ. Nonsteroidal anti-inflammatory drugs (NSAIDs), cyxlooxygenase-2 selective inhibitors (coxibs) and gastrointestinal harm: review of clinical trials and clinical practice. BMC Musculoskelet Disord. 2006;7:79.

24. Lallana MJ, Feja C, Aguilar-Palacio I, Malo S, Rabanaque 
MJ. Use of Non-Steroidal Anti-Inflammatory Drugs and Associated Gastroprotection in a Cohort of Workers. Int J Environ Res Public Health. 2018;15(9). pii: E1836. doi: 10.3390/ ijerph15091836

25. Al Khaja KAJ, Veeramuthu S, Isa HA, Sequeira RP. Prescription audit of NSAIDs and gastroprotective strategy in elderly in primary care. Int J Risk Saf Med. 2017;29:57-68.

26. Kellici S, Dibra A, Dracini XH, Deda L, Fida M, Burazeri G. Evaluation of patterns and appropriate gastro protection in Albanian primary health care users. J Biol Regul Homeost Agents. 2013;27:247-251.

27. Areia M, Pereira AD, Banhudo A, Coutinho G. Non-steroidal anti-inflammatory drugs and gastroprotection gap among Family Physicians: Results from a survey. GE Jornal Português de Gastrenterologia. 2013;20:237-239.

28. Scarpignato C, Lanas A, Blandizzi C, Lems WF, Hermann $\mathrm{M}$, Hunt RH, et al. Safe prescribing of non-steroidal antiinflammatory drugs in patients with osteoarthritis--an expert consensus addressing benefits as well as gastrointestinal and cardiovascular risks. BMC Med. 2015;13:55.

29. Targownik LE, Metge CJ, Leung S. Underutilization of gastroprotective strategies in aspirin users at increased risk of upper gastrointestinal complications. Aliment Pharmacol Ther. 2008;28:88-96.
30. Lanas A, Garcia-Tell G, Armada B, Oteo-Alvaro A. Prescription patterns and appropriateness of NSAID therapy according to gastrointestinal risk and cardiovascular history in patients with diagnoses of osteoarthritis. BMC Med. 2011;9:38.

31. Vonkeman HE, Fernandes RW, van de Laar MA, Vonkeman HE, Fernandes RW, van de Laar MA. Under-utilization of gastroprotective drugs in patients with NSAID-related ulcers. Int J Clin Pharmacol Ther. 2007;45:281-288.

32. Cottrell N, Emmerton L, Denaro C. Heart failure patients' awareness and perceptions of the risk of using NSAIDs: a pilot study. Clin Ther. 2007;29:717-719.

33. Albsoul-Younes AM, Jabateh SK, Abdel-Hafiz SM, Al-Safi SA. Awareness and frequency of potential side effects on nonsteroidal anti-inflammatory drugs among the Jordanian patient population. Saudi Med J. 2004;25:907-911.

34. de Abajo FJ, Gil MJ, Bryant V, Timoner J, Oliva B, GarcíaRodríguez LA. Upper gastrointestinal bleeding associated with NSAIDs, other drugs and interactions: a nested casecontrol study in a new general practice database. Eur J Clin Pharmacol. 2013;69:691-701.

35. Murtezani A. Low back pain among Kosovo power plant workers: a survey. Italian Journal of Public Health. 2012;9(4). doi: $10.2427 / 8661$ 